\title{
Metastatic pathway-specific transcriptome analysis identifies MFSD4 as a putative tumor suppressor and biomarker for hepatic metastasis in patients with gastric cancer
}

\author{
Mitsuro Kanda ${ }^{1, *}$, Dai Shimizu, ${ }^{1, *}$, Haruyoshi Tanaka ${ }^{1}$, Masahiro Shibata $^{1}$, Naoki \\ Iwata $^{1}$, Masamichi Hayashi ${ }^{1}$, Daisuke Kobayashi ${ }^{1}$, Chie Tanaka ${ }^{1}$, Suguru Yamada ${ }^{1}$, \\ Tsutomu Fujii ${ }^{1}$, Goro Nakayama ${ }^{1}$, Hiroyuki Sugimoto ${ }^{1}$, Masahiko Koike ${ }^{1}$, Michitaka \\ Fujiwara $^{1}$ and Yasuhiro Kodera ${ }^{1}$ \\ ${ }^{1}$ Department of Gastroenterological Surgery (Surgery II), Nagoya University Graduate School of Medicine, Nagoya, Japan \\ * These authors have contributed equally to this work \\ Correspondence to: Mitsuro Kanda, email: m-kanda@med.nagoya-u.ac.jp \\ Keywords: gastric cancer, hepatic metastasis, MFSD4, biomarker, tumor suppressor \\ Received: November 04,2015 Accepted: January 29, $2016 \quad$ Published: February 08, 2016
}

\section{ABSTRACT}

Gastric cancer (GC) with hepatic metastasis remains a fatal disease. Global expression profiling was conducted using tissues from patients who had GC with synchronous hepatic metastasis, and major facilitator superfamily domain containing 4 (MFSD4) was identified as a candidate biomarker for hepatic metastasis in GC. Functional and expression analyses of this molecule in GC cell lines and clinical samples were conducted. We analyzed MFSD4 expression, DNA methylation, and copy number. RNA interference experiments evaluated the effects of MFSD4 expression on cell phenotype and apoptosis. We analyzed tissues of 200 patients with GC to assess the diagnostic performance of MFSD4 levels for predicting hepatic recurrence, metastasis, or both. Differential expression of MFSD4 mRNA by GC cell lines correlated positively with the levels of NUDT13 and OCLN mRNAs and inversely with those of BMP2. Hypermethylation of the MFSD4 promoter was detected in cells with lower levels of MFSD4 mRNA. Inhibition of MFSD4 expression significantly increased the invasiveness and motility of GC cells but did not influence cell proliferation or apoptosis. MFSD4 mRNA levels in primary GC tissues were reduced in patients with concomitant hepatic metastasis or recurrence compared with those without. Low levels of MFSD4 mRNA in primary GC tissues were an independent risk factor of hepatic recurrence and metastasis. MFSD4 expression in gastric tissues may represent a useful biomarker for identification of patients at high risk for hepatic recurrence, metastasis, or both.

\section{INTRODUCTION}

Gastric cancer (GC) is one of the most common malignancies and the third leading cause of cancerrelated deaths worldwide $[1,2]$. Hepatic metastasis and relapse contribute to the high incidence of GC-related fatalities, and represent a frequent and crucial problem for oncologists [3, 4]. Metastasis is a multistep process involving detachment from a primary site, invasion of surrounding connective tissue, transmigration across the basement membrane, intravasation, formation of tumor emboli, extravasation, and colonization of target organs $[5,6]$. GC metastasizes through three distinct metastatic pathways; lymphatic, hematogeneous and direct dissemination from the serosal surface [7-9]. Each metastatic pathway is considered to require survival of select clones that accumulate specific mutations or epigenetic abnormalities. Thus, knowledge of the unique molecular attributes of each metastatic pathway will improve our understanding of the biology of metastatic GC and facilitate development of specific biomarkers and appropriate targeted therapies, leading to efficacious personalized treatment [10]. Studies to identify and explore diagnostic biomarkers and molecular targets to predict and treat hepatic metastases among others are warranted. 
To achieve this goal, we conducted transcriptome analysis using a next-generation sequencing platform and identified major facilitator superfamily domain containing 4 (MFSD4) as a candidate biomarker for hepatic metastasis of GC. In the current study, we conducted expression and functional analyses of MFSD4 to validate our global expression profiling data. To our knowledge this is the first study that evaluated significance of MFSD4 in the metastatic process of GC.

\section{RESULTS}

\section{Identification of MFSD4 as an inhibitor of hepatic metastasis}

Transcriptome analysis identified 21 candidate genes (Supplementary Table 1). After literature review regarding current knowledge on functional aspect of each gene, we decided to focus on MFSD4 because 1) MFSD4 exhibited the second strongest suppression in primary GC tissues among 21 candidates (approximately 5\% of the corresponding noncancerous adjacent gastric mucosa), 2) MFSD4 expression levels were comparable between primary GC tissues and liver tissues with metastases, 3) MFSD4 encodes a membrane trafficking protein that may be involved in cellular functions and transportation of growth factors, and 4) we sought novel molecules as potential biomarkers for $\mathrm{GC}$ there have been no reports on oncological roles of MFSD4.

\section{MFSD4 mRNA levels of GC cell lines}

The levels of MFSD4 mRNAs differed among GC cell lines. AGS, N87, NUGC2, NUGC3, and SC-6JCK cells expressed MFSD 4 mRNA at levels that were approximately $<50 \%$ of that of the control cell line FHs74 (Figure 1A). MFSD4 mRNA levels did not differ according to the degree of differentiation of the GC cells.

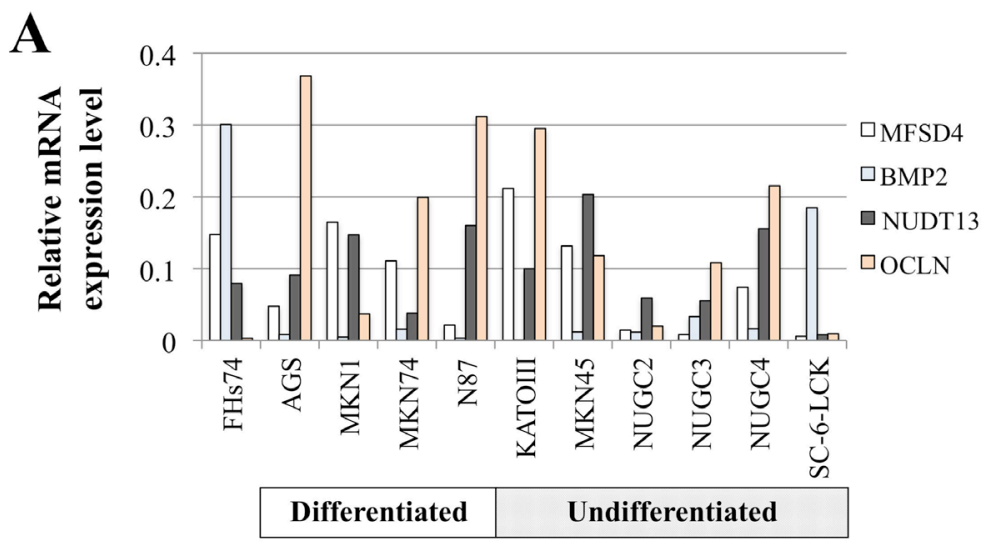

B
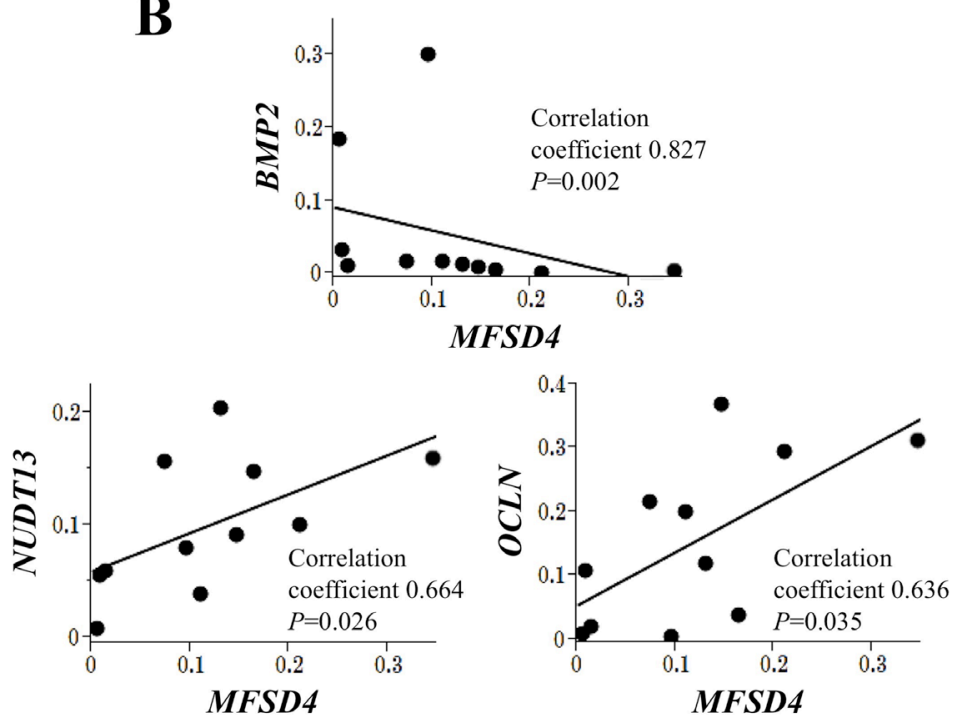

Figure 1: Expression analysis of 10 GC cell lines and the nontumorigenic epithelial cell line FHs74. A. Expression of MFSD4 and genes expressed at similar differential levels were identified using PCR array analysis. B. Analysis of the correlation between the mRNA levels of MFSD4 and those of BMP2, NUDT13, and OCLN. 
A

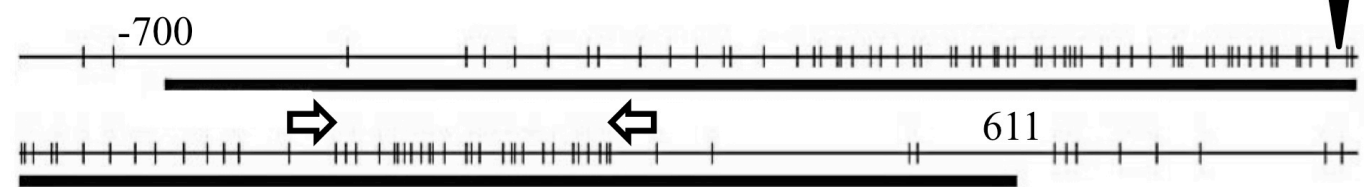

$1+1,1$

CpG island; lengh 1311 bp, \%GC 68.4\% Observed $\mathrm{CpG} /$ Expected $\mathrm{CpG}=69.5 \%$

$\Rightarrow \prec$ Primers for bisulfite sequencing

Transcription start site

B

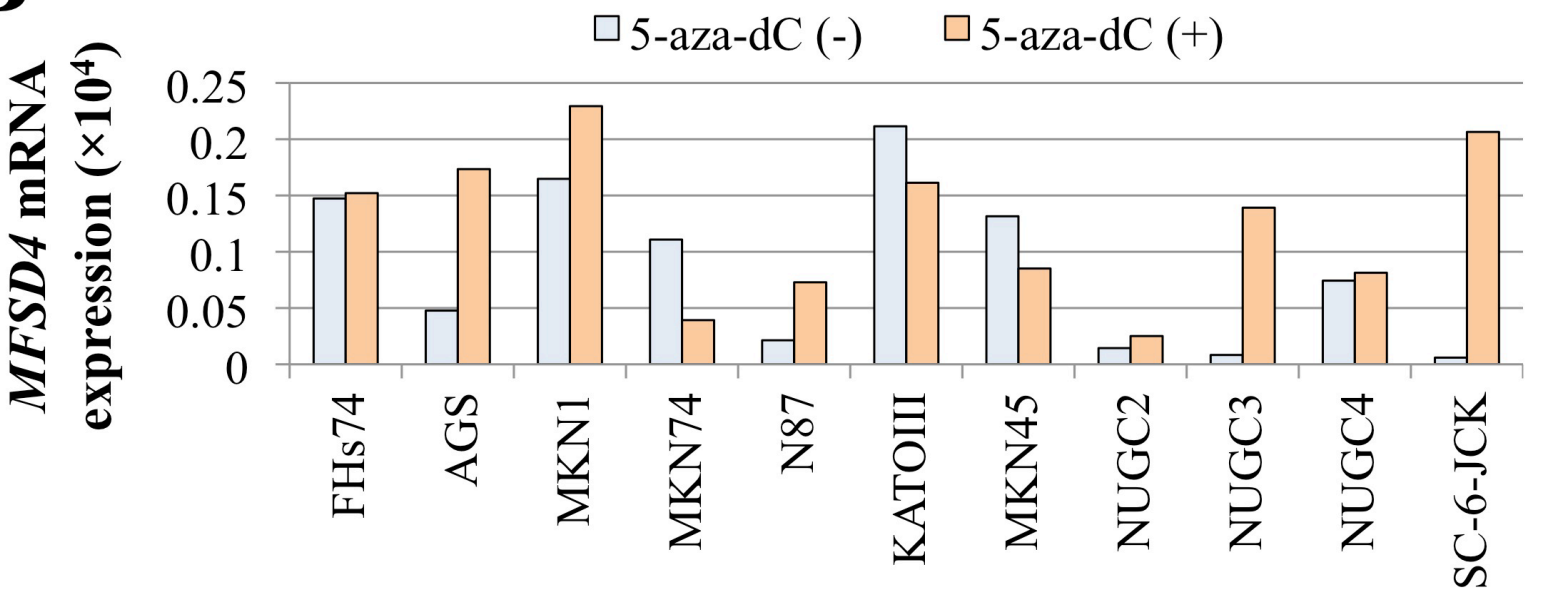

\begin{tabular}{r|c|c|c|c|c|c|c|c|c|c|c|}
\hline Methylation & $\mathrm{U}$ & $\mathrm{M}$ & $\mathrm{U}$ & $\mathrm{U}$ & $\mathrm{M}$ & $\mathrm{U}$ & $\mathrm{M}$ & $\mathrm{U}$ & $\mathrm{M}$ & $\mathrm{U}$ & $\mathrm{M}$ \\
\hline \hline Copy number & 2 & 2 & 2 & 2 & 2 & 2 & 2 & 2 & 2 & 2 & 2 \\
\hline
\end{tabular}

Differentiated

Undifferentiated

C
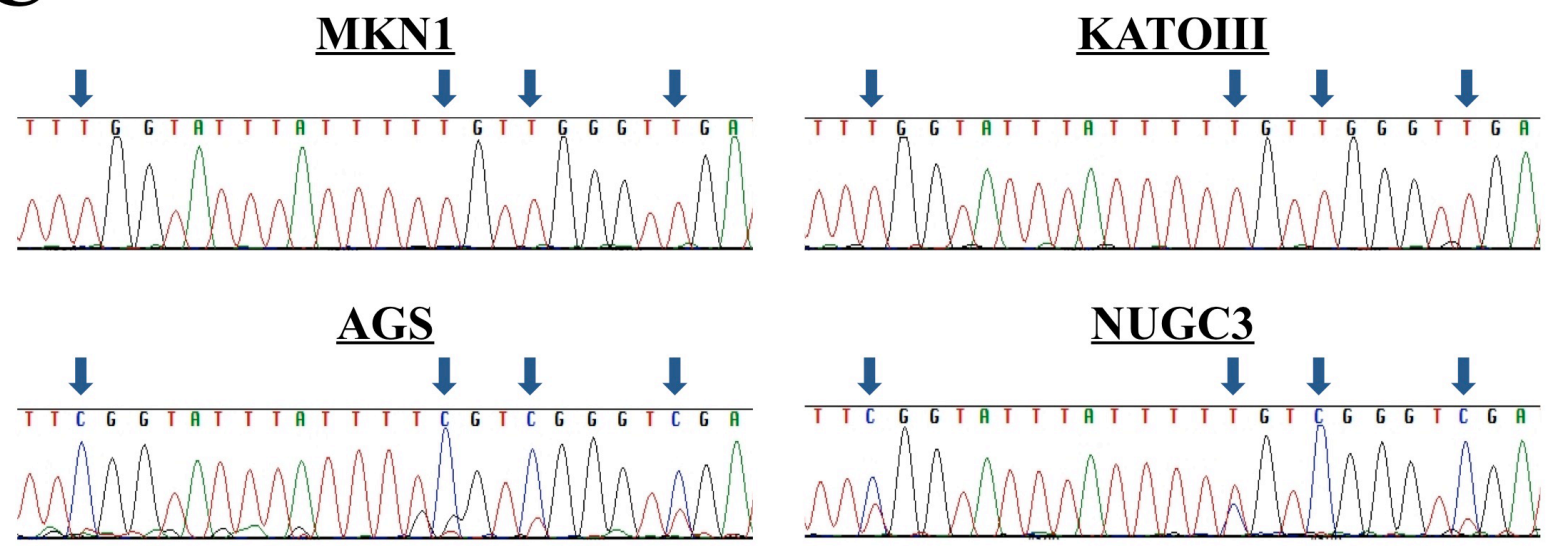

Figure 2: Expression, methylation and gene copy-number analysis. A. A CpG island was detected near the MFSD4 transcriptioninitiation site, extending upstream into the promoter region. B. MFSD4 mRNA levels in 11 cell lines before or after 5-aza-dC treatment. The methylation status of the MFSD4 promoter and the copy number of the MFSD4 locus are shown and summarized in the lower boxes. M, methylated; U, unmethylated. C. Representative bisulfite sequencing data. All CpG sites in AGS cell were retained as CG and those of MKN1 and KATOIII cells were converted to TG. NUGC3 cell showed partial methylation. 
PCR array analysis revealed that $\mathrm{mRNAs}$ encoding nudixtype motif 13 (NUDT13) and occludin (OCLN) were expressed at levels that correlated significantly with those of the mRNA encoding MFSD4, whereas the expression levels of bone morphogenetic protein 2 (BMP2) mRNA correlated inversely with those of MFSD4 (Figures 1A and 1B).

\section{Mechanism of suppression of MFSD4 transcription in GC}

Identification of a $\mathrm{CpG}$ island in the MFSD4 promoter region (Figure 2A) suggested that hypermethylation of the $\mathrm{CpG}$ islands inhibits MFSD4 transcription in GC cells. Bisulfite sequencing analysis revealed that the MFSD4 promoter was methylated in AGS, N87, MKN45, NUGC3, and SC-6-JCK cells. When we compared the levels of MFSD4 mRNAs in GC cell lines before and after demethylation, reactivation of MFSD4 expression was detected in cells with promoter hypermethylation (Figure 2B). Representative results of direct sequence analysis are shown in figure $2 \mathrm{C}$. Moreover, the copy number of the MFSD4 locus of each GC cell line was the same as that of the controls (Figure 2B).

\section{Effect of MFSD4 knockdown on the malignant phenotype and apoptosis of GC cells}

Inhibition of MFSD4 expression using a specific siRNA was conducted to evaluate the function of MFSD4 in GC cells. The effect of MFSD4 knockdown was confirmed using qPCR assays (Figure 3A). We evaluated the proliferation, invasion, migration, and apoptosis of MKN1 (differentiated type) and MKN45 (undifferentiated type) cells, which produced relatively high levels of MFSD4 mRNA. The proliferation rates of these cell lines were not influenced by the inhibition of MFSD4 expression (Figure 3B). In contrast, knockdown of MFSD4 expression significantly increased invasion (Figure 3C) and migration (Figure 3D) of MKN1 cells compared with the untransfected and siControl-transfected cells. The size of the population of apoptotic cells was not altered by knockdown of MFSD4 expression (Supplementary Figure 1). The results for MKN45 cells were similar to those for MKN1 (data not shown).

\section{Clinical implications of MFSD4 mRNA levels in primary GC tissues}

In $177(88.5 \%)$ patients, MFSD4 mRNA expression levels were lower in GC tissues compared to the corresponding noncancerous adjacent tissues. The diagnostic performance of the detection of hepatic metastasis was correlated with the levels of MFSD4 expression in primary GC tissues. There were 11 patients with synchronous hepatic metastasis and nine patients who experienced hepatic recurrences after curative gastrectomy. The AUC value of MFSD4 expression levels was 0.768 for detection of synchronous hepatic metastasis or hepatic recurrence within 2 years after surgery, and the optimal cutoff value $=0.006$ (sensitivity $=80.0 \%$, specificity $=71.1 \%$, Figure $4 \mathrm{~A}$ ). A significant decrease of MFSD4 expression was detected in patients with stage I GC compared with the noncancerous adjacent tissues. The levels of MFSD4 expression were lower in patients with stage II/III GC who experienced hepatic recurrences following curative gastrectomy compared with those without hepatic recurrences, although the difference was not statistically significant. In patients harboring distant metastasis at the time of surgery (stage IV), the levels of MFSD4 expression in primary GC tissues were significantly lower in patients with synchronous hepatic metastasis compared with those without (Figure 4B).

When patients were classified into high and low MFSD4 expression groups according to the proposed cutoff (MFSD4 mRNA level $=0.006)$, the cumulative incidence of findings that indicated recurrences in the form of hepatic metastases were significantly higher in the low MFSD4 group ( $p=0.048$, Figure 4C). MFSD4 mRNA levels were independent of tumor depth, differentiation, and disease stage whereas they were significantly associated with macroscopic type, infiltrative growth type, and metastatic sites (peritoneal or liver) (Table 1). To investigate further the relationship between high MFSD4 mRNA levels in GC tissues and hepatic metastasis, multivariate binomial logistic analysis was conducted and revealed that low MFSD4 levels were an independent risk factor for hepatic metastasis, recurrence, or both (odds ratio 5.28, 95\% confidence interval 1.63-20.6, $p$ =0.005; Table 2). The MFSD4 mRNA levels were not significantly associated with overall survival of the 200 enrolled patients (Supplementary Figure 2A), or overall (Supplementary Figure 2B) and disease-free survival (Supplementary Figure 2C) of patients with stage II/III GC.

\section{DISCUSSION}

Here we conducted a transcriptome analysis to explore metastatic-pathway specific molecules associated with GC and identified MFSD4 as a candidate tumor suppressor and inhibitor of hepatic metastasis. MFSD4 resides on human chromosome $1 \mathrm{q} 32.1$ and is predicted to encode the multi-pass transmembrane protein MFSD4 comprising 514 amino acid residues $(56 \mathrm{kDa})[11,12]$. Although the MFSD4 paralog KIA1919 is involved in glucose transport and is ubiquitously expressed, its biological function is still under investigation [13].

In GC cell lines, MFSD 4 mRNA was expressed at different levels independent of each cell's differentiated 
A

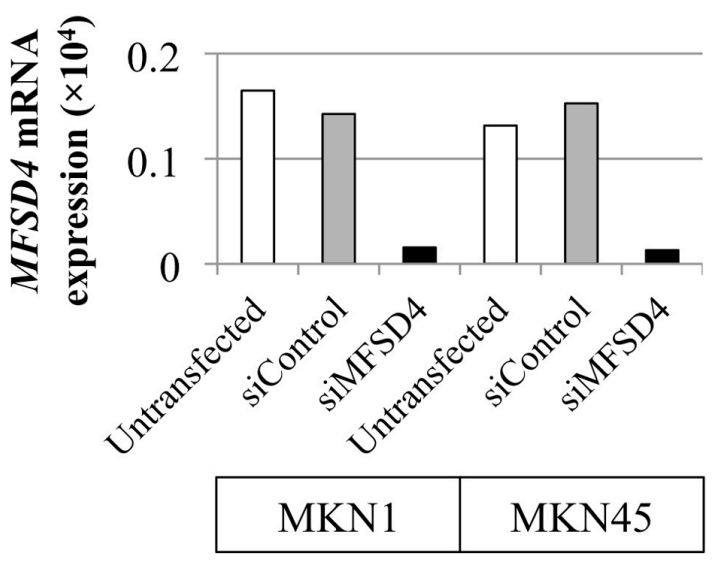

B

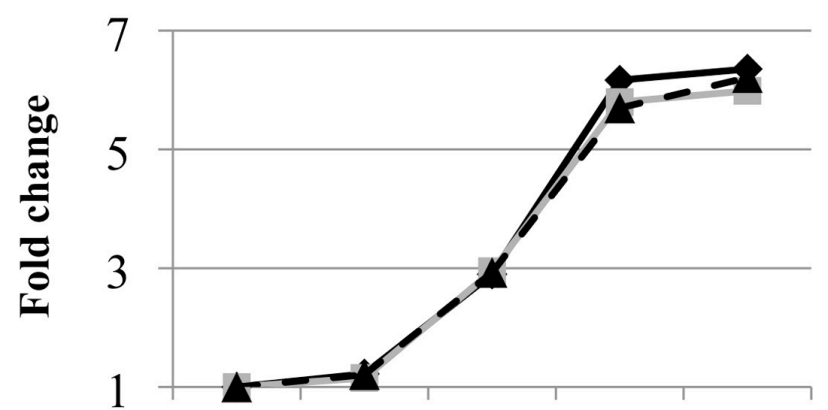

Day 0 Day 1 Day 3 Day 5 Day 7

$\rightarrow$ Untransfected - siControl $-\Delta-\operatorname{siMFSD} 4$

C
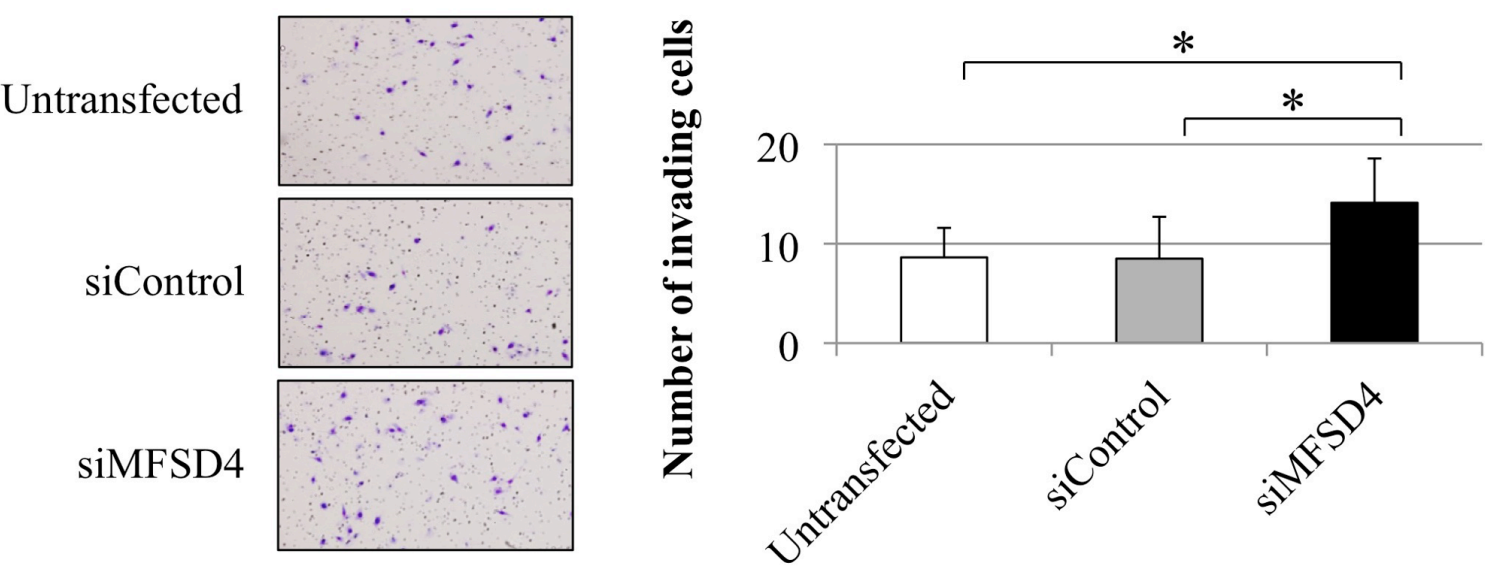

D
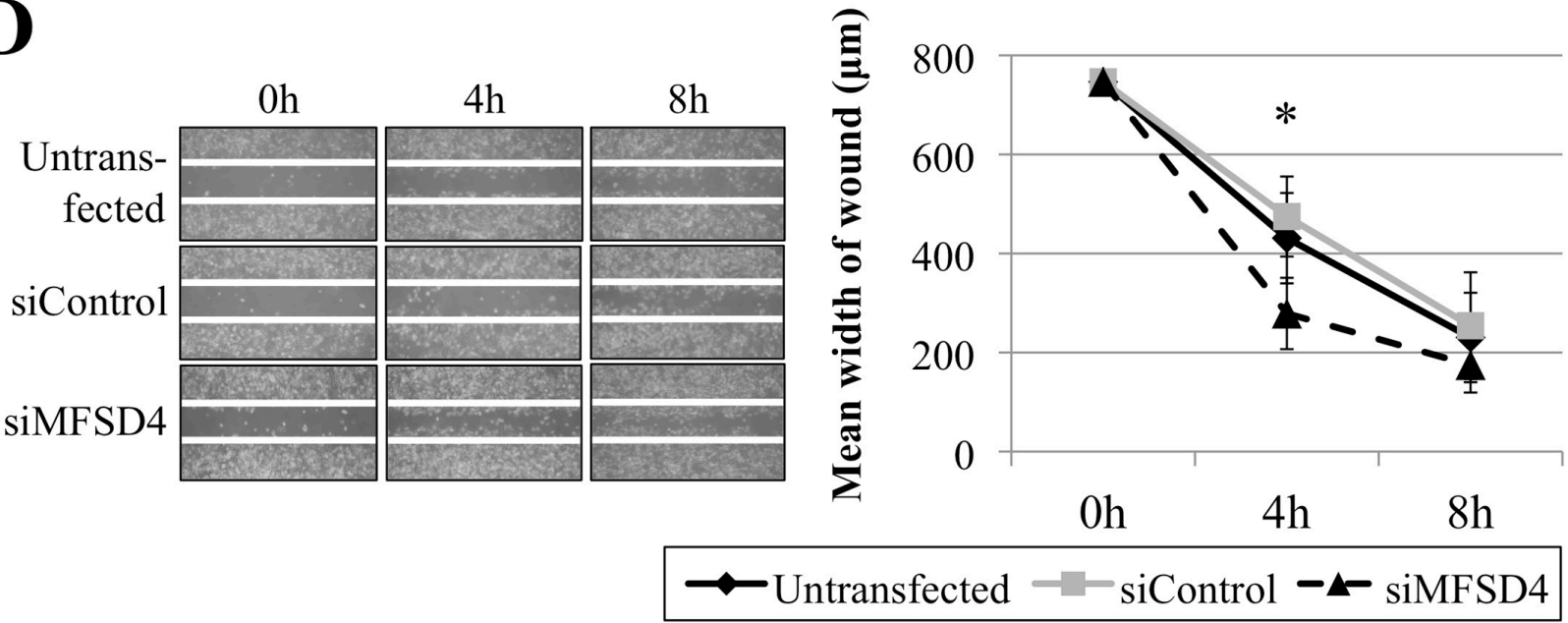

Figure 3: Effects of siRNA-mediated knockdown of MFSD4 expression on GC cells. A. siRNA-mediated MFSD4 knockdown was determined using qPCR. B. Cell proliferation assay. The MFSD4 siRNA had little effect on the proliferation of MKN1 cells. C. Cell invasion assays. The number of invading cells was significantly increased by knockdown of MFSD4 expression. ${ }^{*} p<0.05$. D. Woundhealing cell migration assays. Inhibition of MFSD4 expression significantly increased the migration of MKN1 cells. ${ }^{*} p<0.05$. 

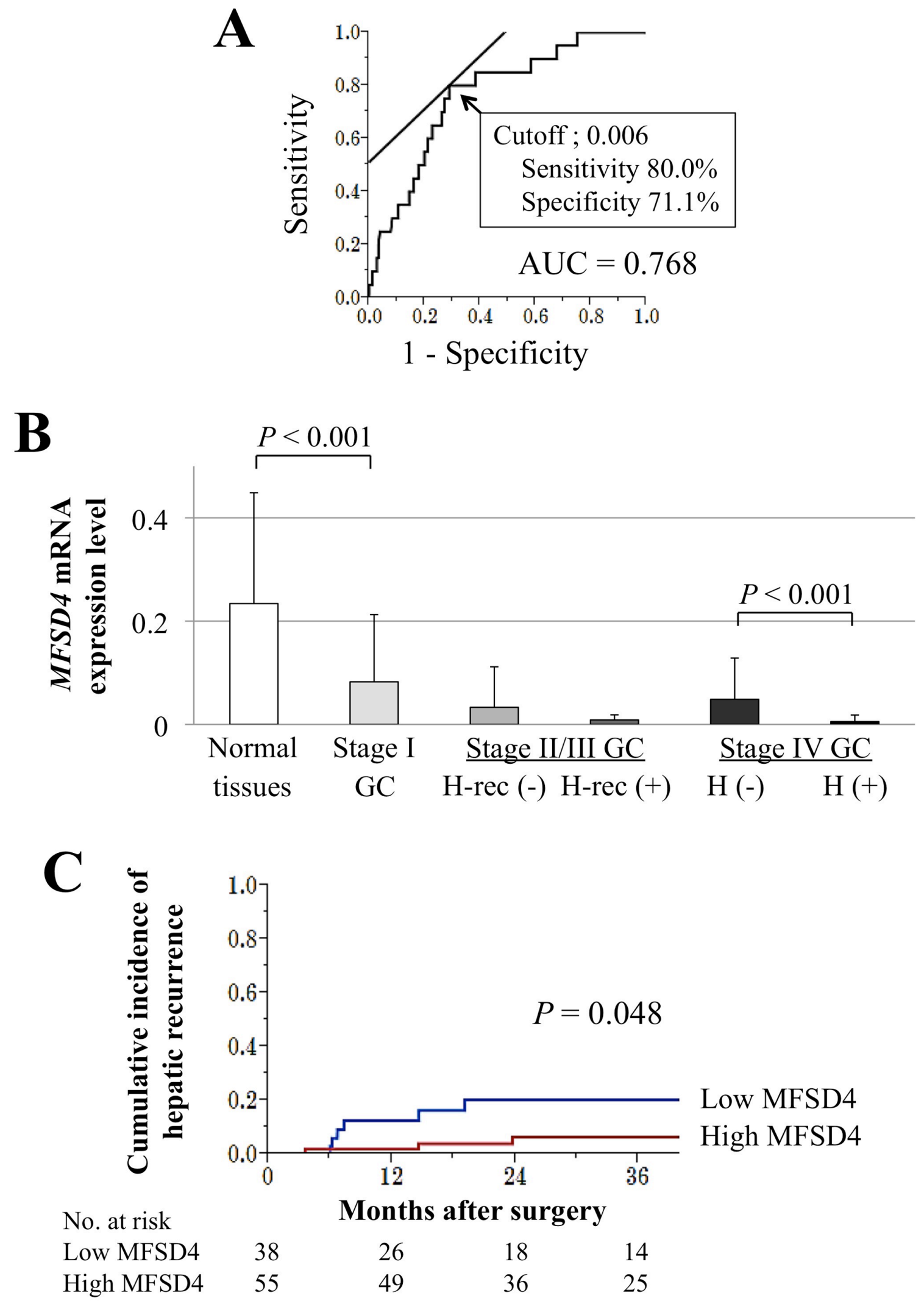

Figure 4: Clinical implications of the levels of MFSD4 mRNA in GC tissues. A. ROC curve analysis of the value of MFSD4 expression levels for predicting hepatic metastasis. The optimal cutoff value $=0.006$. B. The levels of MFSD 4 mRA in the corresponding adjacent noncancerous tissues and GC tissues according to disease stage and recurrence patterns. $\mathbf{C}$. The cumulative incidence of hepatic recurrence was significantly higher in the low-MFSD4 group when focusing on 93 patients with stage II/III GC. GC, gastric cancer; AUC, area under the curve. 
Table 1: Association between MFSD4 mRNA levels and clinicopathological characteristics of 200 patients with gastric cancer

\begin{tabular}{|c|c|c|c|}
\hline \begin{tabular}{|l|} 
Variables \\
\end{tabular} & High MFSD4 & Low MFSD4 & $P$ \\
\hline $\begin{array}{l}\text { Age } \\
<65 \text { year } \\
\geq 65 \text { year }\end{array}$ & $\begin{array}{l}55 \\
74\end{array}$ & $\begin{array}{l}24 \\
47\end{array}$ & 0.219 \\
\hline \begin{tabular}{|l|} 
Sex \\
Male \\
Female \\
\end{tabular} & $\begin{array}{l}88 \\
41 \\
\end{array}$ & $\begin{array}{l}53 \\
18 \\
\end{array}$ & 0.337 \\
\hline $\begin{array}{l}\text { CEA }(\mathrm{ng} / \mathrm{ml}) \\
\leq 5 \\
>5\end{array}$ & $\begin{array}{l}104 \\
25\end{array}$ & $\begin{array}{l}51 \\
20 \\
\end{array}$ & 0.159 \\
\hline $\begin{array}{l}\text { CA19-9 (IU/ml) } \\
\leq 37 \\
>37\end{array}$ & $\begin{array}{l}104 \\
25\end{array}$ & \begin{tabular}{|l}
52 \\
19 \\
\end{tabular} & 0.232 \\
\hline \begin{tabular}{|l} 
Tumor location \\
Entire \\
Upper third \\
Middle third \\
Lower third \\
\end{tabular} & $\begin{array}{l}15 \\
28 \\
38 \\
48 \\
\end{array}$ & \begin{tabular}{|l|}
4 \\
16 \\
19 \\
32 \\
\end{tabular} & 0.438 \\
\hline $\begin{array}{l}\text { Tumor size }(\mathrm{mm}) \\
<50 \\
\geq 50 \\
\end{array}$ & \begin{tabular}{|l}
50 \\
79 \\
\end{tabular} & $\begin{array}{l}23 \\
48 \\
\end{array}$ & 0.369 \\
\hline $\begin{array}{l}\text { Macroscopic type } \\
\text { Borrmann type } 4 / 5 \\
\text { Others } \\
\end{array}$ & $\begin{array}{l}31 \\
98 \\
\end{array}$ & \begin{tabular}{|l|}
5 \\
66 \\
\end{tabular} & $0.002 *$ \\
\hline $\begin{array}{l}\text { Tumor depth (UICC) } \\
\text { pT1-3 } \\
\text { pT4 }\end{array}$ & $\begin{array}{l}55 \\
74\end{array}$ & $\begin{array}{l}39 \\
32 \\
\end{array}$ & 0.096 \\
\hline \begin{tabular}{|l} 
Differentiation \\
Differentiated \\
Undifferentiated \\
\end{tabular} & \begin{tabular}{|l}
44 \\
85 \\
\end{tabular} & $\begin{array}{l}30 \\
41 \\
\end{array}$ & 0.255 \\
\hline \begin{tabular}{|l} 
Lymphatic involvement \\
Absent \\
Present \\
\end{tabular} & \begin{tabular}{|l}
17 \\
112 \\
\end{tabular} & \begin{tabular}{|l}
9 \\
62 \\
\end{tabular} & 0.919 \\
\hline $\begin{array}{l}\text { Vessel invasion } \\
\text { Absent } \\
\text { Present }\end{array}$ & $\begin{array}{l}51 \\
78\end{array}$ & $\begin{array}{l}22 \\
49\end{array}$ & 0.227 \\
\hline $\begin{array}{l}\text { Infiltrative growth type } \\
\text { Invasive growth } \\
\text { Expansive growth } \\
\end{array}$ & $\begin{array}{l}62 \\
67 \\
\end{array}$ & $\begin{array}{l}16 \\
55 \\
\end{array}$ & $<0.001 *$ \\
\hline $\begin{array}{l}\text { Lymph node metastasis } \\
\text { Absent } \\
\text { Present } \\
\end{array}$ & $\begin{array}{l}37 \\
92 \\
\end{array}$ & $\begin{array}{l}20 \\
51 \\
\end{array}$ & 0.939 \\
\hline $\begin{array}{l}\text { Peritoneal lavage cytology } \\
\text { Negative } \\
\text { Positive } \\
\end{array}$ & $\begin{array}{l}86 \\
43 \\
\end{array}$ & \begin{tabular}{|l}
59 \\
12 \\
\end{tabular} & $0.011^{*}$ \\
\hline \begin{tabular}{|l|} 
Synchronous liver metastasis \\
Absent \\
Present \\
\end{tabular} & \begin{tabular}{|l}
128 \\
1 \\
\end{tabular} & \begin{tabular}{|l}
61 \\
10 \\
\end{tabular} & $<0.001 *$ \\
\hline \begin{tabular}{|l} 
UICC stage \\
I \\
II \\
III \\
IV \\
\end{tabular} & $\begin{array}{l}24 \\
17 \\
38 \\
50 \\
\end{array}$ & $\begin{array}{l}8 \\
16 \\
22 \\
25 \\
\end{array}$ & 0.246 \\
\hline
\end{tabular}

*Statistically significant $(p<0.05)$. CEA, carcinoembryonic antigen; CA19-9, carbohydrate antigen 19-9; UICC, Union for International Cancer Control. 
Table 2: Predictive factors of hepatic metastasis/recurrence for 200 patients with gastric cancer

\begin{tabular}{|c|c|c|c|c|c|c|c|c|}
\hline \multirow{2}{*}{\multicolumn{2}{|c|}{ Variables }} & \multirow{2}{*}{ H/ H-rec (-) } & \multirow{2}{*}{ H/ H-rec (+) } & \multicolumn{2}{|c|}{ Univariate } & \multicolumn{3}{|c|}{ Multivariate } \\
\hline & & & & \multirow{2}{*}{\begin{tabular}{|l|} 
OR \\
1.59 \\
\end{tabular}} & \multirow{2}{*}{$\begin{array}{l}\boldsymbol{P} \\
0.352\end{array}$} & \multirow[t]{2}{*}{ OR } & \multirow[t]{2}{*}{$95 \% \mathrm{CI}$} & \multirow[t]{2}{*}{$P$} \\
\hline Age & $\begin{array}{l}<65 \text { year } \\
\geq 65 \text { year }\end{array}$ & $\begin{array}{l}73 \\
107 \\
\end{array}$ & $\begin{array}{l}6 \\
14 \\
\end{array}$ & & & & & \\
\hline Sex & \begin{tabular}{|l} 
Male \\
Female \\
\end{tabular} & \begin{tabular}{|l|}
123 \\
57
\end{tabular} & $\begin{array}{l}18 \\
2 \\
\end{array}$ & 4.17 & 0.027 & 3.28 & $0.73-23.9$ & 0.128 \\
\hline CEA & $\begin{array}{l}\leq 5 \mathrm{ng} / \mathrm{ml} \\
>5 \mathrm{ng} / \mathrm{ml}\end{array}$ & \begin{tabular}{|l|}
144 \\
36
\end{tabular} & $\begin{array}{l}11 \\
9 \\
\end{array}$ & 3.27 & 0.018 & 2.51 & $0.78-8.13$ & 0.122 \\
\hline CA19-9 & $\begin{array}{l}\leq 37 \mathrm{IU} / \mathrm{ml} \\
>37 \mathrm{IU} / \mathrm{ml} \\
\end{array}$ & \begin{tabular}{|l}
143 \\
37 \\
\end{tabular} & $\begin{array}{l}13 \\
7 \\
\end{array}$ & 2.08 & 0.159 & & & \\
\hline Tumor location & $\begin{array}{l}\text { Lower third } \\
\text { Others }\end{array}$ & $\begin{array}{l}71 \\
109\end{array}$ & $\begin{array}{l}9 \\
11\end{array}$ & 0.80 & 0.632 & & & \\
\hline Tumor size & $\begin{array}{l}<50 \mathrm{~mm} \\
\geq 50 \mathrm{~mm}\end{array}$ & $\begin{array}{l}68 \\
112\end{array}$ & $\begin{array}{l}5 \\
15\end{array}$ & 1.82 & 0.248 & & & \\
\hline Macroscopic type & $\begin{array}{l}\text { Borrmann type } 4 \\
\text { Others }\end{array}$ & $\begin{array}{l}35 \\
145 \\
\end{array}$ & $\begin{array}{l}1 \\
20 \\
\end{array}$ & 4.59 & 0.070 & & & \\
\hline Tumor depth & \begin{tabular}{|l|} 
pT1-3 \\
pT4
\end{tabular} & \begin{tabular}{|l|}
82 \\
98 \\
\end{tabular} & $\begin{array}{l}12 \\
8 \\
\end{array}$ & 1.79 & 0.219 & & & \\
\hline Differentiation & \begin{tabular}{|l|} 
Differentiated \\
Undifferentiated
\end{tabular} & $\begin{array}{l}63 \\
117 \\
\end{array}$ & $\begin{array}{l}9 \\
11 \\
\end{array}$ & 2.27 & 0.085 & & & \\
\hline Lymphatic involvement & $\begin{array}{l}\text { Absent } \\
\text { Present }\end{array}$ & $\begin{array}{l}25 \\
155 \\
\end{array}$ & $\begin{array}{l}1 \\
19 \\
\end{array}$ & 3.06 & 0.212 & & & \\
\hline Vessel invasion & \begin{tabular}{|l|} 
Absent \\
Present
\end{tabular} & $\begin{array}{l}72 \\
108 \\
\end{array}$ & $\begin{array}{l}1 \\
19 \\
\end{array}$ & 12.7 & $<0.001$ & 14.4 & $2.62-269$ & $<0.001^{*}$ \\
\hline Infiltrative growth & \begin{tabular}{|l} 
Invasive \\
Expansive
\end{tabular} & $\begin{array}{l}77 \\
103 \\
\end{array}$ & $\begin{array}{l}1 \\
19 \\
\end{array}$ & 14.2 & $<0.001$ & 6.00 & $0.99-116$ & 0.050 \\
\hline Lymph node metastasis & \begin{tabular}{|l|} 
Absent \\
Present
\end{tabular} & \begin{tabular}{|l}
54 \\
126 \\
\end{tabular} & $\begin{array}{l}3 \\
17 \\
\end{array}$ & 2.43 & 0.136 & & & \\
\hline Peritoneal lavage cytology & \begin{tabular}{|l} 
Negative \\
Positive
\end{tabular} & \begin{tabular}{|l}
127 \\
53 \\
\end{tabular} & $\begin{array}{l}18 \\
2 \\
\end{array}$ & 3.76 & 0.044 & 2.80 & $0.59-20.6$ & 0.204 \\
\hline MFSD4 expression & $\begin{array}{l}\text { High } \\
\text { Low }\end{array}$ & \begin{tabular}{|l}
125 \\
55 \\
\end{tabular} & $\begin{array}{l}4 \\
16 \\
\end{array}$ & 9.09 & $<0.001$ & 5.28 & $1.63-20.6$ & $0.005^{*}$ \\
\hline
\end{tabular}

*Statistically significant in multivariate analysis $(p<0.05)$. H/ H-rec, hepatic metastasis/recurrence; OR, odds ratio; CI, confidence interval; CEA, carcinoembryonic antigen; CA19-9, carbohydrate antigen 19-9; UICC, Union for International Cancer Control.

phenotype. EMT is a crucial process for cancer cells to increase the ability to migrate and invade, which are required for the development of metastatic lesions [6, 14]. We found that $N U D T 13$ and $O C L N$ were expressed in concert with $M F S D 4$, and the expression levels of $B M P 2$ correlated inversely with those of MFSD4 in GC cells lines. $B M P 2$ increases the invasiveness of cells via activation of matrix metalloproteinase-2, which is required during the dispersal stage of the EMT [15-18]. NUDT13 is a mitochondrial enzyme, and its expression decreases during the EMT, although its function is unknown [19]. $O C L N$, a $65-\mathrm{kDa}$ tetraspan integral membrane protein, contributes to the stabilization of the intercellular tight junctions and optimal barrier function and is considered an inhibitor of the EMT [20,21]. In the absence of published data on the biological function of MFSD4, our data implicate that MFSD4 participates in the process of EMT through its coordinate expression with other EMTregulating molecules in GC.
Promoter hypermethylation leads to the transcriptional silencing of tumor suppressor genes [22-24]. We show here that MFSD4-promoter hypermethylation was frequently accompanied by inhibition of MFSD4 transcription. Further, MFSD4 mRNA levels increased in cells treated with a DNA methylation inhibitor. These findings indicate that promoter hypermethylation is a pivotal mechanism that inhibits MFSD4 transcription. To the best of our knowledge, this is the first report of the hypermethylation of MFSD4. In contrast, MFSD4 expression was not reactivated after de-methylation in MKN45 and NUGC2 cells. We assume that other mechanisms inhibit MFSD4 transcription, such as $\mathrm{LOH}$, because the MFSD4 locus resides within a known hotspot of chromosomal alterations. However, there was no detectable difference in MFSD4 copy numbers among the GC cell lines. Other regulatory mechanisms, such as histone modification and point mutations, might be also responsible for suppression 
of MFSD4 in some GC cells. Further, we show here that inhibition of MFSD4 expression contributed to the migration and invasion of GC cell lines but not to proliferation and apoptosis. These findings suggested that suppression of MFSD4 plays a crucial role in tumor progression and highlighted its usefulness as a potential therapeutic target in GC.

In surgically-resected gastric tissues, $88.5 \%$ of patients had lower MFSD4 mRNA expression levels in GC tissues compared to the corresponding noncancerous adjacent tissues, and decreased MFSD4 expression was found at the earliest stage of GC. These findings indicated that MFSD4 may play a tumor suppressor-like role in pathogenesis of GC. Our findings that the levels of MFSD4 mRNA in GC tissues serve as an independent risk factor for hepatic recurrence and metastasis indicates the potential of MFSD4 expression as a novel diagnostic or predictive biomarker for hepatic metastasis in patients with GC. Evaluation of MFSD4 expression may be useful for preoperative staging, postoperative monitoring, and selection of optimal multimodal strategy. For example, physicians may be able to stratify patients at risk for hepatic metastasis at the time of endoscopic biopsy or surgical resection of the primary GC, enabling them to provide appropriate management to treat concurrent or future hepatic metastasis. Moreover, the value of MFSD4 expression for the prognosis of hepatic metastasis will be enhanced by the development of assays to detect MFSD4 expression or methylation in serum samples because of the use of a relatively noninvasive technique that can be frequently repeated. Interestingly, the expression of MFSD4 had no significant association with vessel invasion, which is known as a typical risk factor for hepatic metastasis. This finding may highlight more the utility of MFSD4 for stratifying patients at risk of hepatic metastasis independent of vessel invasion. On the other hand, MFSD4 expression had no association with lymph node metastasis, though it was significantly associated with positive lavage cytology, which meant that MFSD4 may be involved also in formation of peritoneal metastasis for some extent. Possible reasons that MFSD4 expression had no association with lymph node metastasis are given as follows. In this study, only presence or absence of lymph node metastasis was evaluated regardless of the number and location of the metastatic nodes. Since GC frequently metastases to the regional lymph nodes even in the earlier stage of the disease, the presence of lymph node metastasis may not always reflect the aggressiveness of GC. Moreover, each metastatic pathway has different underlying molecular mechanisms and suppression of MFSD4 may facilitate hepatic (hematogenous) metastasis without influencing on lymphatic metastasis.

The present study has certain limitations. First, extensive expression analyses of proteins that potentially interact with MFSD4 must be conducted to further understand the biological functions of MFSD4 in GC. Second, this study was limited by the relatively small sample size and lack of external validation of the reproducibility of the expression assays and their standardization across laboratories. Finally, better understanding of the tumor-suppressive functions of MFSD4 can be potentially gained by the enforced expression of MFSD4 in mouse xenograft models.

Nevertheless, taken together, our findings indicate that decreased MFSD4 expression was associated with hepatic metastasis and that MFSD4 acts as a tumor suppressor in GC by inhibiting the malignant phenotype of cancer cells. MFSD4 expression in gastric tissues represents a promising biomarker for identification of patients at high risk for hepatic metastasis.

\section{MATERIALS AND METHODS}

\section{Transcriptome analysis}

Surgically resected gastric and liver specimens of four patients with GC and synchronous hepatic metastasis were subjected to transcriptome analysis. The four patients had one or two metastatic lesions confined in the unilateral robe of the liver but no other distant metastases (e.g. lung, bone, brain, peritoneal and distant lymph nodes) and received the sufficient information necessary to give informed consent before surgery. Global expression profiling was conducted using the HiSeq platform (Illumina, San Diego, CA) to compare the expression levels of 57761 genes among the primary GC tissues, the corresponding noncancerous adjacent gastric mucosae, and hepatic metastases. In the current study, we decided to focus on MFSD4 which was identified as one of candidate genes in the transcriptome analysis.

\section{Sample collection}

Ten GC cell lines were used in this study. MKN1, MKN45, MKN74, NUGC2, NUGC3, NUGC4 and SC6-JCK were obtained from the Japanese Collection of Research Bioresources Cell Bank (JCRB, Osaka, Japan) and AGS, KATOIII and N87 were from the American Type Culture Collection (ATCC, Manassas, VA, USA). A control, non-tumourigenic epithelial cell line (FHs74) was purchased from ATCC. The cell lines have been tested using the short tandem repeat -polymerase chain reaction method and authenticated by the JCRB Cell Bank on January 2015. Cell lines were cultured at $37^{\circ} \mathrm{C}$ in Dulbecco's modified Eagle's medium (DMEM; SigmaAldrich, St. Louis, MO, USA) supplemented with 10\% fetal bovine serum (FBS) in an atmosphere containing $5 \% \mathrm{CO}_{2}$. Primary $\mathrm{GC}$ tissues and the corresponding noncancerous adjacent tissues were collected from 200 patients who underwent gastric resection for $\mathrm{GC}$ at the 
Department of Gastroenterological Surgery, Nagoya University Hospital between 2001 and 2014. These samples were collected consecutively, except that samples from pretreated patients and those from early-stage cancer from which sufficient amount of samples were unavailable were excluded. The tissue samples were immediately frozen in liquid nitrogen and stored at $-80{ }^{\circ} \mathrm{C}$. Relevant clinical data including clinical stages according to the 7th edition of the Union for International Cancer Control (UICC) classification system were retrieved from the prospectively compiled database at the department. The tumor infiltrative pattern has been routinely evaluated by hematoxylin and eosin stained sections as a pathological characteristic of surgically resected specimens and classified into expansive and invasive growth types according to clarity of the tumor border [25]. This study conforms to the ethical guidelines of the World Medical Association Declaration of Helsinki - Ethical Principles for Medical Research Involving Human Subjects, and written informed consent for the use of clinical samples and data, as required by the Institutional Review Board at Nagoya University, Japan, was obtained from all patients.

\section{Analysis of MFSD4 mRNA levels}

MFSD4 mRNA levels were determined using a quantitative real-time reverse-transcription polymerase chain reaction (qRT-PCR) assay. Total RNAs (10 $\mu \mathrm{g}$ per sample), which were isolated from 11 cell lines and 200 primary GC tissues as well as the corresponding noncancerous adjacent tissues were used to generate complementary DNAs after a quality check by measuring the optical density to confirm that the ratio of the absorbance at 260 and $280 \mathrm{~nm}$ ranges from 1.8 to 2.0. The RT-PCR amplification reaction was performed as follows: Initial denaturation at $95{ }^{\circ} \mathrm{C}$ for $10 \mathrm{~min}, 40$ cycles at 95 ${ }^{\circ} \mathrm{C}$ for $10 \mathrm{~s}$, and at $60^{\circ} \mathrm{C}$ for $30 \mathrm{~s}$. All samples were tested in triplicate, and samples without template were included in each PCR plate as a negative control. A SYBR-Green PCR core reagents kit (Applied Biosystems, Foster City, CA, USA) was used to perform qRT-PCR, and realtime detection of SYBR-Green fluorescence emission intensity was performed using an ABI StepOnePlus RealTime PCR System (Applied Biosystems). The levels of glyceraldehyde-3-phosphate dehydrogenase (GAPDH) mRNA were quantified in each sample, and the expression level of each sample was calculated as the value of MFSD4 mRNA divided by that of GAPDH mRNA [26, 27]. Primers are listed in Supplementary Table 2.

\section{PCR array analysis of gene expression}

To analyze gene expression in $10 \mathrm{GC}$ cell lines and the FHs74 cell line, we used the Human Epithelial to Mesenchymal Transition (EMT) RT ${ }^{2}$ Profiler PCR Array
(Qiagen, Hilden, Germany) comprising 84 key genes, including those that encode proteins that function in the processes as follows: transcription, extracellular matrix formation, epithelial to mesenchymal transition (EMT), differentiation, morphogenesis, growth, proliferation, migration, cytoskeletal formation [28].

\section{Methylation analysis of MFSD4}

The nucleotide sequence of the MFSD4 promoter region was analyzed to determine the presence or absence of $\mathrm{CpG}$ islands defined as follows: $\geq 200$-bp region of DNA with a high GC content ( $>50 \%)$ and an Observed $\mathrm{CpG} /$ Expected $\mathrm{CpG}$ ratio $\geq 0.6$. We used $\mathrm{CpG}$ Island Searcher software (http://cpgislands.usc.edu/) to determine the locations of $\mathrm{CpG}$ islands [29, 30]. Genomic DNAs of the cell lines were treated with bisulfite for bisulfite sequence analysis. After PCR amplification using specific primers (Supplementary Table 2), PCR products were subcloned into a TA cloning vector (Invitrogen, Carlsbad, CA, USA). The DNAs were mixed with $3 \mathrm{~mL}$ of a specific primer (M13) and $4 \mathrm{~mL}$ of Cycle Sequence Mix (ABI PRISM Terminator v1. 1 Cycle Sequencing Kit; Applied Biosystems). Sequence analysis was conducted using an Applied Biosystems ABI310, and sequence electropherograms were generated using ABI Sequence Analysis 3.0 software (Applied Biosystems). To assess the relation of promoter hypermethylation to MFSD4 transcription, GC cells $\left(1.5 \times 10^{6}\right)$ were treated with 5-aza-2'-deoxycytidine (5-aza-dC) (Sigma-Aldrich) to inhibit DNA methylation and then cultured for 6 days with medium changes on days 1,3 , and 5. RNA was extracted, and qRT-PCR was performed as described [31].

\section{Copy number analysis}

Using purified genomic DNA obtained from cell lines, the copy number MFSD4 was determined using TaqMan Copy Number Assays (Applied Biosystems). Genomic DNAs (20 ng per cell line) were amplified using specific primer pairs using an ABI StepOnePlus Real-Time PCR System (Applied Biosystems) according to the manufacturer's instructions. Two assays were employed as follows: upstream (assay ID: Hs01431727 cn, within the exon 1 of MFSD4) and downstream (assay ID: Hs00149995_cn within the exon 10 of MFSD4). Data were analyzed using CopyCaller Software (Life Technologies) [32].

\section{Knockdown of MFSD4 expression using a small interfering RNA (siRNA)}

The Accell siRNA transfection method (Dharmacon, Lafayette, CO, USA) was used to transfect an siRNA 
specific for MFSD4 mRNA (siMFSD4) into MKN1 and MKN45 cells that expressed relatively high levels of MFSD4 mRNA. The control siRNA was designated siControl [33]. After transfection, cells were incubated with serum-free DMEM (Sigma-Aldrich) for $72 \mathrm{~h}$. The MFSD4 mRNA levels of transfected (siControl, siMFSD4) and untransfected cells were determined using qPCR.

\section{Cell proliferation assay}

Cell proliferation was evaluated using the Premix WST-1 Cell Proliferation Assay System (Takara Bio Inc., Japan). MKN1 and MKN45 cells $\left(5 \times 10^{3}\right.$ cells per well) were seeded into 96-well plates in DMEM supplemented with $2 \%$ FBS and incubated for 7 days. The optical density of the solution in each well was measured on days 1, 3, 5 and 7 following the addition of $10 \mu \mathrm{l}$ of WST-1.

\section{Cell invasion assay}

The ability of GC cells to invade Matrigel was determined using BioCoat Matrigel invasion chambers (BD Biosciences, Bedford, MA, USA) according to the manufacturer's protocol. MKN1 and MKN45 cells $(2.5 \times$ $10^{4}$ cells per well) were seeded into the upper well of the chamber in serum-free DMEM. After $48 \mathrm{~h}$, cells on the lower surface of the membrane were fixed, stained, and counted using a microscope (200× magnification, eight randomly selected fields).

\section{Wound-healing assay}

The migration of GC cells was evaluated using wound-healing assays. MKN1 and MKN45 cells $\left(2 \times 10^{4}\right.$ cells per well) were seeded into 12-well plates in serumfree DMEM using the ibidi Culture insert method (ibidi, Martinsried, Germany) to establish wound gaps of a defined width. After $24 \mathrm{~h}$, the insert was removed, and the width of the wound as a function of time was measured at $100-\mu \mathrm{m}$ intervals ( 20 per well, $40 \times$ magnification).

\section{Apoptosis assay}

The effect of MFSD4 knockdown on induction of apoptosis was analyzed using the FITC Annexin V/Dead Cell Apoptosis Kit with FITC annexin V and PI for Flow Cytometry (Invitrogen, Carlsbad, CA, USA) according to the manufacturer's instruction. Briefly, control, siMFSD4transfected and ultraviolet-light irradiated (60 s) MKN1 cells were washed in phosphate-buffered saline and centrifuged. Cells $\left(5 \times 10^{5} \mathrm{cell} / \mathrm{s} / \mathrm{ml}\right)$ were incubated with 5 $\mu \mathrm{L}$ of FITC annexin $\mathrm{V}$ and $100 \mathrm{ng}$ of propidium iodide and incubated at room temperature for $15 \mathrm{~min}$. The cells were analyzed using a flow cytometer (BD FACSAria Fusion;
BD Biosciences, Bedford, MA, USA).

\section{Statistical analysis}

The significance of the difference between two variables was assessed using Spearman's rank correlation coefficient. The Mann-Whitney test was used to compare the differences between two groups. Goodness-of-fit was assessed by calculating the area under the curve (AUC) of the receiver operating characteristic (ROC) curve, and the optimal cutoff value was determined using the Youden index. Associations between MFSD4 mRNA levels and clinical variables were evaluated using Fisher's exact test or the chi-square test. Risk factors for hepatic metastasis were evaluated using binomial logistic analysis. Overall survival rates were calculated using the Kaplan-Meier method, and the difference between survival curves was analyzed using the log-rank test. All statistical analyses were performed using JMP 10 software (SAS Institute Inc., Cary, NC, USA). A value of $p<0.05$ was considered statistically significant.

\section{CONFLICTS OF INTEREST}

The authors declare no conflict of interest.

\section{REFERENCES}

1. Siegel R, Naishadham D, and Jemal A. Cancer statistics, 2012. CA Cancer J Clin. 2012; 62: 10-29.

2. Kanda M, and Kodera Y. Recent advances in the molecular diagnostics of gastric cancer. World J Gastroenterol. 2015; 21: 9838-52.

3. Hartgrink HH, Jansen EP, van Grieken NC, and van de Velde CJ. Gastric cancer. Lancet. 2009; 374: 477-90.

4. Shen L, Shan YS, Hu HM, Price TJ, Sirohi B, Yeh KH, Yang YH, Sano T, Yang HK, Zhang X, Park SR, Fujii M, Kang YK, et al. Management of gastric cancer in Asia: resource-stratified guidelines. Lancet Oncol. 2013; 14: e535-47.

5. De Mattos-Arruda L, Bidard FC, Won HH, Cortes J, Ng CK, Peg V, Nuciforo P, Jungbluth AA, Weigelt B, Berger MF, Seoane J, and Reis-Filho JS. Establishing the origin of metastatic deposits in the setting of multiple primary malignancies: the role of massively parallel sequencing. Mol Oncol. 2014; 8: 150-8.

6. Lamouille S, Xu J, and Derynck R. Molecular mechanisms of epithelial-mesenchymal transition. Nat Rev Mol Cell Biol. 2014; 15: 178-96.

7. Gonzalez CA, and Agudo A. Carcinogenesis, prevention and early detection of gastric cancer: where we are and where we should go. Int J Cancer. 2012; 130: 745-53.

8. Kanda M, Murotani K, Kobayashi D, Tanaka C, Yamada S, Fujii T, Nakayama G, Sugimoto H, Koike M, Fujiwara M, 
and Kodera Y. Postoperative adjuvant chemotherapy with S-1 alters recurrence patterns and prognostic factors among patients with stage II/III gastric cancer: A propensity score matching analysis. Surgery. 2015; 158:1573-80.

9. McLean MH, and El-Omar EM. Genetics of gastric cancer. Nat Rev Gastroenterol Hepatol. 2014; 11: 664-74.

10. Kanda M, Nomoto S, Oya H, Takami H, Shimizu D, Hibino S, Hashimoto R, Kobayashi D, Tanaka C, Yamada S, Fujii T, Nakayama G, Sugimoto H, et al. The Expression of Melanoma-Associated Antigen D2 Both in Surgically Resected and Serum Samples Serves as Clinically Relevant Biomarker of Gastric Cancer Progression. Ann Surg Oncol. 2016; 23 Suppl 2:214-21.

11. Ota T, Suzuki Y, Nishikawa T, Otsuki T, Sugiyama T, Irie R, Wakamatsu A, Hayashi K, Sato H, Nagai K, Kimura K, Makita H, Sekine M, et al. Complete sequencing and characterization of 21,243 full-length human cDNAs. Nat Genet. 2004; 36: 40-5.

12. Nguyen LN, Ma D, Shui G, Wong P, Cazenave-Gassiot A, Zhang X, Wenk MR, Goh EL, and Silver DL. Mfsd2a is a transporter for the essential omega-3 fatty acid docosahexaenoic acid. Nature. 2014; 509: 503-6.

13. Spinola M, Falvella FS, Colombo F, Sullivan JP, Shames DS, Girard L, Spessotto P, Minna JD, and Dragani TA. MFSD2A is a novel lung tumor suppressor gene modulating cell cycle and matrix attachment. Mol Cancer. 2010; 9: 62.

14. Wu Q, Hou X, Xia J, Qian X, Miele L, Sarkar FH, and Wang Z. Emerging roles of PDGF-D in EMT progression during tumorigenesis. Cancer Treat Rev. 2013; 39: 640-6.

15. Kodach LL, Jacobs RJ, Voorneveld PW, Wildenberg ME, Verspaget HW, van Wezel T, Morreau H, Hommes DW, Peppelenbosch MP, van den Brink GR, and Hardwick JC. Statins augment the chemosensitivity of colorectal cancer cells inducing epigenetic reprogramming and reducing colorectal cancer cell 'stemness' via the bone morphogenetic protein pathway. Gut. 2011; 60: 1544-53. .

16. Liao A, Wang W, Sun D, Jiang Y, Tian S, Li J, Yang X, and Shi R. Bone morphogenetic protein 2 mediates epithelialmesenchymal transition via AKT and ERK signaling pathways in gastric cancer. Tumour Biol. 2015; 36: 2773-8.

17. Yang Y, Yang C, and Zhang J. C23 protein meditates bone morphogenetic protein-2-mediated EMT via up-regulation of Erk1/2 and Akt in gastric cancer. Med Oncol. 2015; 32: 76.

18. McCormack N, and O'Dea S. Regulation of epithelial to mesenchymal transition by bone morphogenetic proteins. Cell Signal. 2013; 25: 2856-62.

19. McLennan AG. The Nudix hydrolase superfamily. Cell Mol Life Sci. 2006; 63: 123-43.

20. Chen Y, Zhang HS, Fong GH, Xi QL, Wu GH, Bai CG, Ling ZQ, Fan L, Xu YM, Qin YQ, Yuan TL, Sun H, and Fang J. PHD3 Stabilizes the Tight Junction Protein Occludin and Protects Intestinal Epithelial Barrier Function. J Biol Chem. 2015; 290: 20580-9.
21. Cummins PM. Occludin: one protein, many forms. Mol Cell Biol. 2012; 32: 242-50.

22. Kanda M, Sugimoto $H$, and Kodera Y. Genetic and epigenetic aspects of initiation and progression of hepatocellular carcinoma. World J Gastroenterol. 2015; 21: 10584-97.

23. Bird A. Perceptions of epigenetics. Nature. 2007; 447: 3968.

24. Kanda M, Sugimoto $H$, Nomoto $S$, Oya H, Hibino S, Shimizu D, Takami H, Hashimoto R, Okamura Y, Yamada S, Fujii T, Nakayama G, Koike M, et al. Bcell translocation gene 1 serves as a novel prognostic indicator of hepatocellular carcinoma. Int J Oncol. 2015; 46: 641-8.

25. Song KY, Hur H, Jung CK, Jung ES, Kim SN, Jeon HM, and Park CH. Impact of tumor infiltration pattern into the surrounding tissue on prognosis of the subserosal gastric cancer (pT2b). Eur J Surg Oncol. 2010; 36: 563-7.

26. Kanda M, Nomoto S, Oya H, Hashimoto R, Takami H, Shimizu D, Sonohara F, Kobayashi D, Tanaka C, Yamada S, Fujii T, Nakayama G, Sugimoto H, et al. Decreased expression of prenyl diphosphate synthase subunit 2 correlates with reduced survival of patients with gastric cancer. J Exp Clin Cancer Res. 2014; 33: 88. .

27. Kanda M, Nomoto S, Oya H, Shimizu D, Takami H, Hibino S, Hashimoto R, Kobayashi D, Tanaka C, Yamada S, Fujii T, Nakayama G, Sugimoto H, et al. Dihydropyrimidinaselike 3 facilitates malignant behavior of gastric cancer. J Exp Clin Cancer Res. 2014; 33: 66. .

28. Kanda M, Shimizu D, Fujii T, Sueoka S, Tanaka Y, Ezaka K, Takami H, Tanaka H, Hashimoto R, Iwata N, Kobayashi D, Tanaka C, Yamada S, et al. Function and diagnostic value of Anosmin-1 in gastric cancer progression. Int $\mathrm{J}$ Cancer. 2016; 138:721-30.

29. Kanda M, Shimizu D, Nomoto S, Hibino S, Oya H, Takami H, Kobayashi D, Yamada S, Inokawa Y, Tanaka C, Fujii T, Sugimoto H, Koike M, et al. Clinical significance of expression and epigenetic profiling of TUSC1 in gastric cancer. J Surg Oncol. 2014; 110: 136-44.

30. Kanda M, Shimizu D, Nomoto S, Takami H, Hibino S, Oya H, Hashimoto R, Suenaga M, Inokawa Y, Kobayashi D, Tanaka C, Yamada S, Fujii T, et al. Prognostic impact of expression and methylation status of DENN/MADD domain-containing protein 2D in gastric cancer. Gastric Cancer. 2015; 18: 288-96. 0.

31. Kanda M, Oya H, Nomoto S, Takami H, Shimizu D, Hashimoto R, Sueoka S, Kobayashi D, Tanaka C, Yamada S, Fujii T, Nakayama G, Sugimoto H, et al. Diversity of clinical implication of B-cell translocation gene 1 expression by histopathologic and anatomic subtypes of gastric cancer. Dig Dis Sci. 2015; 60: 1256-64.

32. Ezaka K, Kanda M, Sugimoto H, Shimizu D, Oya H, Nomoto S, Sueoka S, Tanaka Y, Takami H, Hashimoto R, Okamura Y, Yamada S, Fujii T, et al. Reduced Expression of Adherens Junctions Associated Protein 1 Predicts 
Recurrence of Hepatocellular Carcinoma After Curative Hepatectomy. Ann Surg Oncol. 2015; 22 Suppl 3: 1499507.

33. Oya H, Kanda M, Sugimoto H, Shimizu D, Takami $\mathrm{H}$, Hibino S, Hashimoto R, Okamura Y, Yamada S, Fujii T, Nakayama G, Koike M, Nomoto S, et al. Dihydropyrimidinase-like 3 is a putative hepatocellular carcinoma tumor suppressor. J Gastroenterol. 2015; 50: 590-600. 